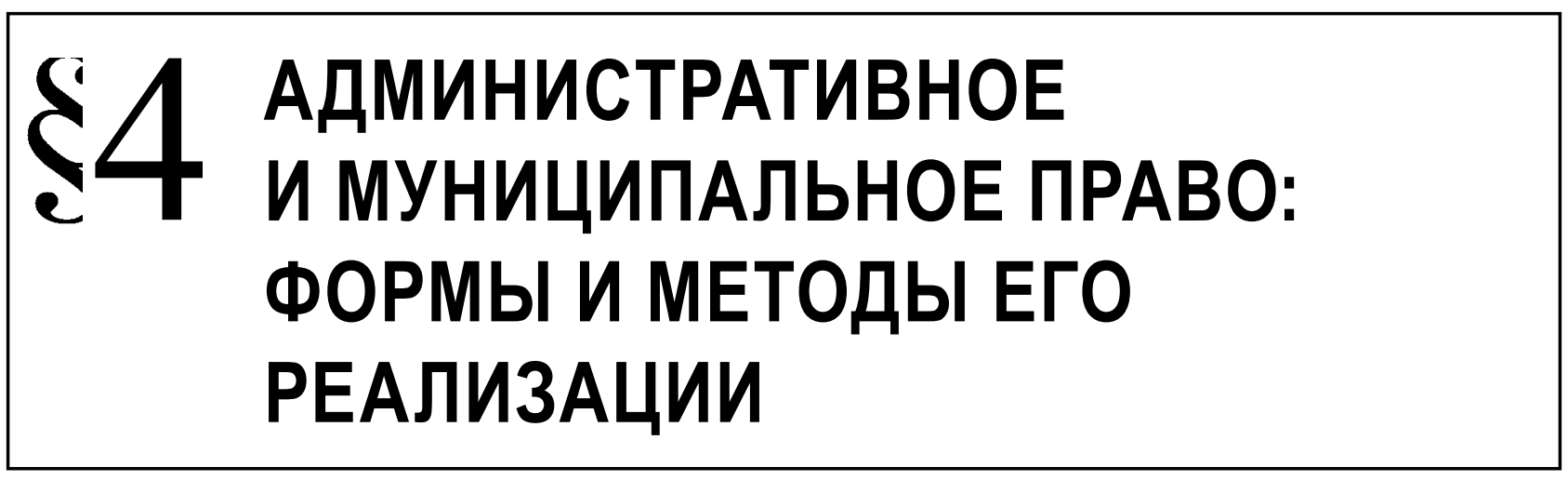

Чвякин В.A.

\title{
ОБРАЗОВАТЕЛЬНЫЙ КЛАСТЕР ВУЗОВ И ПРАКТИЧЕСКАЯ КОНСУЛЬТАТИВНО - ПСИХОЛОГИЧЕСКАЯ И ПРАВОВАЯ РАБОТА С МОЛОДЕЖЬЮ КАК СОЦИАЛЬНАЯ ОСНОВА ПРОФИЛАКТИКИ ПОДРОСТКОВОЙ ПРЕСТУПНОСТИ И АДМИНИСТРАТИВНОЙ ДЕЛИКТНОСТИ В РОССИИ
}

Аннотация. В статье представлены актуальные с позиций административной деликтности несовершеннолетних сведения. В качестве объекта исследования рассматривается девиантное поведение несовершеннолетних правонарушителей и подростков, склонных к правонарушениям. Предметом исследования в статье являются социально - психологические особенности личности и индивидуально - психологические черты характера (акцентуации), структура которых определяет морально - нравственную регуляцию поведения, ценностные ориентации личности подростка и особенности его девиантного поведения.Показано, что в социально - психологическом отношении девиантное поведение подростков представляет довольно значимую проблему. Это связано с тем, что отклоняющееся поведение характерно для большинства подростков и его многие исследователи считают возрастной поведенческой нормой. С другой стороны, отклоняющееся поведение представляет собой риск развития социально - аномальных дерормаций личности, при которых девиантное поведение является опасным для окружающих. Крайним вариантом в этом ряду следует считать делинквентное, то есть противоправное поведение подростков, которые совершают преступления различной тяжести. Методологическую основу статьи составили современные достижения теории познания. В процессе исследования применялись общефилософский, теоретический, общефилософские методы (диалектика, системный метод, анализ, синтез, аналогия, дедукция, наблюдение, моделирование), традиционно правовые методы (формально-логический), а также методы, используемые в конкретно-социологических исследованиях (статистические, экспертные оценки и др.). В настоящее время преступность несовершеннолетних правонарушителей характеризуется особой дерзостью, цинизмом и полным отсутствием морально - нравственной регуляции поведения. Динамика структурных, мотивационных и иных криминологически значимых в социально - психологическом отношении характеристик правонарушений несовершеннолетних подтверждает необходимость значительной активизации и более широкого применения мер социального контроля в качестве нормативного регулятора поведения и целеполагания личности несовершеннолетних правонарушителей.

Ключевые слова: Кластер, Высшее образование, Подмосковье, Молодежь, Патриотическое воспитание, Психологическое консультирование, Поведенческие реакции, деликт, Профилактика, Преступность.

Review. The article presents the information, important from the viewpoint of administrative juvenile delinquency. The object of the research is deviant behavior of minor offenders and juveniles inclined to committing offences. The subject of the research is a range of social and psychological peculiarities of a personality and individual psychological traits of character (accentuations), the structure of which determines the moral regulation of behavior, the value orientations of the personality of a juvenile and the peculiarities of its deviant behavior. The paper shows that in a 
socio-psychological relation deviant behavior of juveniles is a very important problem. Deviant behavior is typical for most of minors and is considered by many researchers as an age-specific norm of behavior. On the other hand, deviant behavior causes a risk of the development of socio-abnormal deformations of a person when deviant behavior is dangerous for other people. The extreme variant of it is a delinquent, i.e. unlawful behavior of minors committing crimes of different weight. The methodology of the research is based on the recent achievements of epistemology. The author uses the general philosophical and theoretical methods (dialectics, the systems method, analysis, synthesis, analogy, deduction, observation, modeling), the traditional legal methods (formal-logical), and the methods used in special sociological studies (the statistical methods, expert assessments, etc.). At present juvenile delinquency is characterized by impudence, cynicism and the absence of moral regulations of behavior. The dynamics of structural, motivational and other characteristics of juvenile delinquency, which are important in a socio-psychological relation, proves the need to use more actively the measures of social control as a normative regulator of behavior and personal goal-setting of minor offenders.

Keywords: behavioral responses, psychological consulting, patriotic education, youth, Moscow area, higher education, cluster, delict, prevention, crime.

$\mathrm{B}$ зависимости от типа кластера (отраслевого или образовательного) и масштаба вуза выделяют несколько стратегий участия учреждений высшей школы в деятельности кластеров. В случае с отраслевыми кластерами университеты могут: 1) инициировать их создание; 2) участвовать - в одном или сразу нескольких кластерах (моно- и мультикластерная стратегии). В случае с образовательными кластерами, вузы могут кооперироваться либо с другими вузами, либо со школами, учреждениями СПО (соответственно, стратегии образовательного кластера определяются как горизонтальная или вертикальная).

В рамках пилотных инновационных кластеров (по типу они сугубо отраслевые) заметны три модели взаимодействия вузов с предприятиями:

1) реализация образовательных программ по приоритетным для участников кластера направлениям подготовки, переподготовки и повышения квалификации кадров, прежде всего инженерных;

2) проведение прикладных исследований совместно с бизнесом;

3) совместное использование инновационной инфраструктуры вузов.

Одним из прикладных направлений деятельности в структуре образовательного кластера, по - видимому, должна быть социально - ориентированная работа, направленная на профилактику различных неблагоприятных и негативных явлений в молодежной среде. Дело в том, что кластер подмосковных вузов может позволить более эффективно решать задачи по патриотическому воспитанию молодых людей, формировать у них чувство гордости за свой вуз и за свое отечество в целом.

Кроме того, в связи с появлением террористических угроз значительно возросла потреб- ность в оказании практической психологической помощи населению. Особенно это относится к жителям крупных регионов, поскольку среди них в гораздо большей мере выражены дезадаптивные варианты поведения, обусловленные акцентуациями характера, психопатиями личности и многими другими пограничными нервно-психическими расстройствами. Следует отметить, что подростки и юноши Подмосковья также, как и их ровесники - москвичи гораздо чаще других слоев населения проявляют свою активность в виде различных вариантов отклоняющегося поведения. Это беспокоит не только родителей и членов семей, но часто и самих молодых людей, так как они испытывают в связи с этим внутреннее напряжение, тревогу, неуверенность и беспокойство. Социальная сущность угроз террористических актов как раз и направлена на поддержание страха среди населения. Молодые люди в таких условиях жизнедеятельности представляют собой особый контингент населения. Именно среди них зарождаются и начинают функционировать экстремистски направленные группировки, которые сами по себе представляют фактор социального напряжения [1 12].

В связи с этим следует отметить, что одна из главных тенденций переходного возраста - переориентация общения с родителей, учителей и вообще старших на ровесников. Потребность в общении со сверстниками, которых не могут заменить родители, возникает у детей довольно рано, а с возрастом усиливается. Поведение же подростков по самой сути своей является коллективно - групповым. Общение со сверстниками представляет очень важный специфический канал информации, по которому подростки узнают многие необходимые вещи, не сообщаемые им взрослыми. Напри- 
мер, подавляющую часть информации по вопросам пола подросток получает от сверстников $[6,10]$.

К тому же, общение подростков - это специфический вид межличностных отношений. Групповая игра и другие виды совместной деятельности вырабатывают необходимые предпосылки социального взаимодействия, умение подчиняться коллективной дисциплине и в то же время отстаивать свои права, соотносить личные интересы с общественными. И, наконец, это специфический вид эмоционального контакта. Сознание групповой принадлежности, солидарности, товарищеской взаимопомощи не только облегчает подростку автономизацию от взрослых, но и дает ему чрезвычайно важное чувство эмоционального благополучия и устойчивости $[2,13]$.

Психология общения в подростковом периоде и юношеском возрасте строится на основе противоречивого переплетения двух потребностей: обособления и потребности в принадлежности, включенности в какую-нибудь группу или общность.

Чувство одиночества, неприкаянности, связанное с возрастными трудностями становления личности, порождает у подростков неутомимую жажду общения и группирования со сверстниками, в обществе которых они находят или надеются найти то, в чем отказывают взрослые: эмоциональное тепло, спасение от скуки и признание собственной значительности. Некоторые психологи считают общение ведущей деятельностью подросткового и юношеского возраста $[2,3,4]$. Напряженная потребность в общении превращается у многих ребят в непреодолимое «стадное чувство»: они не могут не только дня, но часа пробыть вне своей, а если своей нет - какой угодно компании. Особенно сильна такая потребность у мальчиков.

Типичная черта подростковых групп - чрезвычайно высокая конформность. С яростью отстаивая свою независимость от старших, подростки зачастую абсолютно не критически относятся к мнению собственной группы и ее лидеров. Неокрепшее диффузное «Я» нуждается в сильном «МЫ», которое в свою очередь утверждается в противоположность каким-то «ОНИ» $[3,5]$.

Страстное желание быть как все (а «все» - это исключительно «свои») распространяется и на одежду, и на вкусы, и на стиль поведения. Такое противоречие, когда индивидуальность утверждается через единообразие, часто становится источником юношеской тревожности. Тем не менее, это единообразие тщательно поддерживается, и тому, кто рискует бросить вызов, приходится выдержи- вать нелегкую борьбу. Чем примитивнее сообщество, тем нетерпимее оно к индивидуальным различиям, инакомыслию и вообще непохожести.

Психологам и педагогам важно знать особенности подросткового возраста не только в плане психологических и социальных подходов, но и в плане подростковой психиатрии. Здесь необходимо обратить внимание на определенные формы типичных поведенческих реакций подростков на ту или иную социальную ситуацию, еще не являющихся патологическими, но иногда таящими в себе опасность перерастания в «краевые психопатии».

К вышеупомянутым реакциям принято относить реакции оппозиции, имитации, компенсации, гиперкомпенсации, эмансипации, группирования и некоторые другие реакции, обусловленные формирующимся половым влечением $[7,17]$.

Реакция «оппозиции» - это активный протест, ее причиной могут быть слишком высокие требования, предъявляемые к подростку, непосильные нагрузки, утраты, недостаток внимания со стороны взрослых. Возникая в детстве, оппозиция усиливается в подростковом возрасте.

Реакция «имитации» проявляется в стремлении подражать определенному образцу, модель которого диктуется, как правило, компанией сверстников. Реакция может быть причиной нарушения поведения, если образец для подражания асоциальный.

Реакция «гиперкомпенсации» выражается в настойчивом стремлении подростка добиться успеха в той области, в которой он слаб; неудачи в некоторых случаях заканчиваются нервным срывом.

Реакция «эмансипации» проявляется в стремлении освободиться от опеки, контроля и покровительства старших. Она распространяется и на порядки, законы и «стандарты» взрослых. Потребность в эмансипации связана с борьбой за самостоятельность, за самоутверждение себя как личности. В повседневном поведении это - стремление сделать все «по-своему», в крайних вариантах - уходы и побеги из дома.

Реакция «группирования» - филогенетический стадный инстинкт. Группы в среде подростков возникают и функционируют по своим, еще недостаточно изученным социально-психологическим законам, среди которых наибольшую опасность представляет так называемая «автономная мораль», не совпадающая с требованиями родителей, школы, законов. Особенно сильна она у несовершеннолетних правонарушителей и преступников. 
Именно группа становится регулятором поведения для педагогически запущенных подростков. Особенно легко объединяются в группы наркоманы, социально распущенные, неустойчивые подростки, имеющие опыт асоциального поведения.

За последние годы существенно расширилась мотивация таких групп: если раньше это преимущественно были группы общения, то теперь в них представлены разные мотивы участия. Увеличилась доля групп, имеющих общепризнанных лидеров. Что же касается идеологической направленности, то здесь тенденции явно противоречивы. С одной стороны, увеличилось число явно или потенциально антиобщественных групп, с другой стороны, все больше групп хотят или готовы получить официальный статус и сотрудничать с властями.

Юношеская субкультура не является чем-то независимым, цельным и законченным. Ее содержание всегда производно от культуры взрослых и большею частью вторично по отношению к ней. Она весьма неоднородна, включая в себя множество разных, подчас враждебных друг другу течений. Она текуча и изменчива, но в то же время реальна и имеет целый ряд постоянных компонентов: специфический набор ценностей, норм поведения, определенные вкусы, формы одежды и внешнего вида, чувство групповой общности и солидарности, характерную манеру поведения, жаргон, ритуалы.

В юношеских увлечениях проявляется и реализуется очень важное для формирования личности чувство принадлежности: чтобы быть вполне «своим», нужно и выглядеть «как все» и разделять общие увлечения. Мода для подростка - это средство самовыражения, где он всячески подчеркивает свое отличие от «взрослого», даже мода становится средством коммуникации и идентификации.

Центральным психологическим процессом развития самосознания в периоде ранней юности является формирование личной идентичности, чувства индивидуальной самотождественности, преемственности и единства [7].

Обычно к этапу «зрелой идентичности» молодые люди приходят в возрасте 16-18 лет, хотя некоторые могут навсегда остаться на уровне размытой идентичности или пойти путем досрочной идентификации, отказавшись от активного выбора и самоопределения. Вместе с тем понятие «зрелой идентичности» и сами его критерии неоднозначны. Представление, что идентичность формируется, прежде всего, в сфере профессиональной ориентации, отражает традиционно мужскую точ- ку зрения. У девушек дело обстоит иначе. В женском самосознании большое значение придается семье, профессии, хотя в последнее время все больше становится «феминисток», ориентированных, как и мужчины, на профессиональные достижения. Юноши оценивают себя главным образом по своим предметным достижениям, в то время как для девушек важнее межличностные отношения. Отсюда - разное соотношение компонентов мужской и женской идентичности. Юноша, не осуществивший профессионального самоопределения, не может чувствовать себя взрослым. Девушка же может основывать свои притязания на взрослость на других показателях, например на наличии серьезных претендентов на ее руку и сердце.

В отличие от подростков, юноши гораздо более обеспокоены формированием собственных убеждений, развитием мировоззрения. По данным зарубежных психологов, самовосприятие подростков ориентируется на внешние стандарты (учебные отметки и т.д.). Примерно в 16 лет появляются собственные критерии значимости, а 17-18-летние оценивают себя, прежде всего, с точки зрения своей внутренней шкалы ценностей, представлений о своем счастье и благополучии. Замечено также, что при переходе от подросткового возраста к юношескому самоописания становятся более субъективными, психологическими [18].

Главное психологическое приобретение ранней юности - открытие своего внутреннего мира. Для ребенка единственной осознаваемой реальностью является внешний мир. Вполне осознавая свои поступки, он еще не осознает собственных психических состояний. Если ребенок сердится, то объясняет это тем, что его кто-то обидел, если радуется, то этому тоже находится объективное объяснение. Для юноши внешний мир - только одна из возможностей субъективного опыта, средоточием которого является он сам. Обретая способность погружаться в себя, в свои переживания, юноша заново открывает целый мир новых эмоций, красоту природы, звуки музыки. В это время человек начинает воспринимать и осмысливать эмоции уже не как производные от каких-то внешних событий, а как состояние собственного «Я» [5].

Вышеизложенные обстоятельства и целый ряд других представляют собой основание для формирования трудных психологических состояний у молодежи Москвы. В таких условиях личность молодого человека невольно подвергается ощутимой деформации, нуждается в психологической помощи. 
В настоящее время имеются различные подходы в оказании практической психологической помощи населению различных возрастов. Однако применительно к психологическому консультированию молодежи чрезвычайно важную роль играет личность самого психолога-консультанта. Установлено, что ему в обязательном порядке должны быть присущи следующие профессионально-важные черты:

- умение проявлять глубокий интерес к людям и терпение в общении с ними;

- чувствительность к установкам и поведению других людей;

- эмоциональная стабильность и объективность;

- способность вызывать доверие других людей;

- уважать права и чувства других людей.

Таким образом, необходимость психологического консультирования молодежи в современных условиях обусловлена многочисленными данными объективного характера, которые касаются проблем молодого возраста. Успешность оказания практической психологической помощи таким людям во многом зависит от личности самого консультанта, который должен соответствовать необходимым требованиям (зрелость, глубина отношений, личная ответственность и др.). Именно научно-обоснованный подход к психологическим особенностям подросткового и юношеского возраста позволяет в процессе консультативно-психологических мероприятий обеспечивать профилактику подростковой преступности. В процессе консультативно - психологической работы психологи и педагоги должны использовать сведения социальной, клинической психологии, а также умело осуществлять социально - психологическое научение молодых людей по обеспечению собственной безопасности в современных условиях.

\section{Библиография:}

1. Аванесов Г.А. Криминология и социальная профилактика.-М.: Академия МВД СССР, 1990.

2. Айхорн А. Трудный подросток. - М.: Эксмо-Пресс, 2001.

3. Арзуманян С.Д. Микросреда и отклонения социального поведения детей и подростков.-Ереван: Луис, 1980.

4. Аронсон Э., Уилсон Т., Эйкерт Р. Психологические законы поведения человека в социуме. - М.: Прайм-Еврознак, 2004.

5. Баклушинский С.А. Я-концепция и ценностно-нормативные ориентации подростка в условиях быстрых социальных изменений: Автореф. дис. канд. психол. наук. - М., 1996.

6. Бандура А., Уолтерс Р. Подростковая агрессия (изучение влияния воспитания и семейных отношений). - М., 2000.

7. Белинская Е.П., Куликова И.В. Представление подростков о своем будущем в ситуации социального кризиса. - М., 1996.

8. Брянсков И.В., Сергеева В.В., Баталин Д.Е. Применение альтернативных видов наказания в Западной Европе, США и России: сравнительно-правовое исследование. М.: РОО «Центр содействия реформе уголовного правосудия», 2004.

9. Девиантность и социальный контроль в России.-СПб.: Алетейя, 2000.

10. Егоров А.Ю., Игумнов С. А.. Расстройство поведения у подростков. Клинико-психологические аспекты. - СПб.: Речь, 2005.

11. Заключение Экспертного Совета при Уполномоченном по правам человека в РФ по теме: «Первоочередные меры по защите прав детей и детства в Российской Федерации»//Вопросы ювенальной юстиции, 2002.-№ 3.-С. 72-80.

12. Костенников М.В., Куракин А.В. Актуальные проблемы административного права. - М., 2013.

13. Кудрявцев В.Н. Правовое поведение: норма и патология. - М., 1982.

14. Морозов В.М., Ковалев О.Г., Морозов А.М. Психологическая служба и социальная работа в пенитенциарных учреждениях ФРГ: Учеб.-метод. Пособие. - Владимир, 2002.

15. Склярова Т.В., Ярская-Смирнова Е.Р. Этика социальной работы: учебное пособие. - Саратов, 1999.

16. Социальный контроль над девиантностью/ИСИ РАН. - СПб., 1998.

17. Чвякин В.А. Психолого - педагогическое исследование феноменологии антидисциплинарного поведения подростков//Полицейская деятельность. - М., 2015.-№2.

18. Чудновский В.С., Кржечковский А.Ю., Можейко А.А. Самосознание подростков с гармоничным и отклоняющимся поведением.-Ставрополь, 1993.-141 с.

19. Куракин А.В., Костенников М.В., Мышляев Н.П. Правовое регулирование деятельности полиции по профилактики правонарушений в зарубежных государствах // Полицейская деятельность. - 2015. - 1. - С. 24 - 34. DOI: 10.7256/2222-1964.2015.1.14255.

\section{References (transliterated):}

1. Avanesov G.A. Kriminologiya i sotsial'naya profilaktika.-M.: Akademiya MVD SSSR, 1990. 
2. Aikhorn A. Trudnyi podrostok. - M.: Eksmo-Press, 2001.

3. Arzumanyan S.D. Mikrosreda i otkloneniya sotsial'nogo povedeniya detei i podrostkov.-Erevan: Luis, 1980.

4. Aronson E., Uilson T., Eikert R. Psikhologicheskie zakony povedeniya cheloveka v sotsiume. - M.: Praim-Evroznak, 2004.

5. Baklushinskii S.A. Ya-kontseptsiya i tsennostno-normativnye orientatsii podrostka v usloviyakh bystrykh sotsial'nykh izmenenii: Avtoref. dis. kand. psikhol. nauk. - M., 1996.

6. Bandura A., Uolters R. Podrostkovaya agressiya (izuchenie vliyaniya vospitaniya i semeinykh otnoshenii). - M., 2000.

7. Belinskaya E.P., Kulikova I.V. Predstavlenie podrostkov o svoem budushchem v situatsii sotsial'nogo krizisa. - M., 1996.

8. Bryanskov I.V., Sergeeva V.V., Batalin D.E. Primenenie al'ternativnykh vidov nakazaniya v Zapadnoi Evrope, SShA i Rossii: sravnitel'no-pravovoe issledovanie. M.: RO0 «Tsentr sodeistviya reforme ugolovnogo pravosudiya», 2004.

9. Deviantnost' i sotsial'nyi kontrol' v Rossii.-SPb.: Aleteiya, 2000.

10. Egorov A.Yu., Igumnov S. A.. Rasstroistvo povedeniya u podrostkov. Kliniko-psikhologicheskie aspekty. - SPb.: Rech', 2005.

11. Zaklyuchenie Ekspertnogo Soveta pri Upolnomochennom po pravam cheloveka v RF po teme: «Pervoocherednye mery po zashchite prav detei i detstva v Rossiiskoi Federatsii»//Voprosy yuvenal'noi yustitsii, 2002.-№ 3.-S. 72-80.

12. Kostennikov M.V., Kurakin A.V. Aktual'nye problemy administrativnogo prava. - M., 2013.

13. Kudryavtsev V.N. Pravovoe povedenie: norma i patologiya. - M., 1982.

14. Morozov V.M., Kovalev O.G., Morozov A.M. Psikhologicheskaya sluzhba i sotsial'naya rabota v penitentsiarnykh uchrezhdeniyakh FRG: Ucheb.-metod. Posobie. - Vladimir, 2002.

15. Sklyarova T.V., Yarskaya-Smirnova E.R. Etika sotsial'noi raboty: uchebnoe posobie. - Saratov, 1999.

16. Sotsial'nyi kontrol' nad deviantnost'yu/ISI RAN. - SPb., 1998.

17. Chvyakin V.A. Psikhologo - pedagogicheskoe issledovanie fenomenologii antidistsiplinarnogo povedeniya podrostkov// Politseiskaya deyatel'nost'. - M., 2015.-№2.

18. Chudnovskii V.S., Krzhechkovskii A.Yu., Mozheiko A.A. Samosoznanie podrostkov s garmonichnym i otklonyayushchimsya povedeniem.-Stavropol', 1993.-141 s.

19. Kurakin A.V., Kostennikov M.V., Myshlyaev N.P. Pravovoe regulirovanie deyatel'nosti politsii po profilaktiki pravonarushenii v zarubezhnykh gosudarstvakh // Politseiskaya deyatel'nost'. - 2015. - 1. - C. 24 - 34. D0I: 10.7256/22221964.2015.1.14255. 